\title{
Conditioned taste aversion produced by low doses of alcohol*
}

\author{
MICHAEL J. ECKARDT, ARLIE J. SKURDAL, and JUDSON S. BROWN \\ University of Oregon Medical School, Portland, Oregon 97201
}

\begin{abstract}
A taste-aversion paradigm was utilized to demonstrate the aversiveness of intraperitoneal injections of alcohol. When injections followed immediately the ingestion of an originally preferred flavor, the extent of subsequent aversion to that flavor varied as a function of dosage $(1.2 \mathrm{~g}$ alcohol $/ \mathrm{kg}>0.8 \mathrm{~g} / \mathrm{kg}>$ $0.4 \mathrm{~g} / \mathrm{kg}>0.0 \mathrm{~g} / \mathrm{kg}$ ). Delayed injections of $1.2 \mathrm{~g} / \mathrm{kg}$, however, did not result in significant aversion. Significant aversiveness was also demonstrated in a second experiment which utilized a "blind-injection" technique at the $1.2-\mathrm{g} / \mathrm{kg}$ dose level.
\end{abstract}

It is becoming increasingly evident that alcohol, especially when injected intraperitoneally, has aversive behavioral consequences, either peripheral or central in origin. Freed (1967), for example, has obtained behavioral data supporting the suggestion that IP injections in rats have stressful attributes that summate with other stressors such as electric shock. More recently, Barry and Wallgren (1968) have stated that nonisotonic or high-concentration alcohol solutions may produce hemorrhagic lesions of the peritoneal and gastrointestinal membranes if injected parenterally. We know of only one investigation, however, that provides direct support for the contention that ethanol has aversive behavioral consequences. In that study, Lester, Nachman, and Le Magnen (1970) followed a taste-aversion conditioning procedure under which the ingestion of a $0.1 \%$ sodium saccharin solution was followed immediately by a single dose of alcohol administered, in different groups, via an intracardiac, intragastric, or intraperitoneal route. The intraperitoneal doses ranged from 0.74 to $4.42 \mathrm{~g} / \mathrm{kg}$, but only those that produced severe intoxication or a comatose condition resulted in unequivocally significant decreases in saccharin consumption on a subsequent drinking test. Although Lester et al (1970) provided no behavioral or pharmacological criteria for severe intoxication, they were probably referring to the effects of doses of approximately $2.94 \mathrm{~g} / \mathrm{kg}$ or more. A $1.45 \mathrm{-g} / \mathrm{kg}$ dose depressed saccharin intake slightly but not significantly, whereas a dose of $0.74 \mathrm{~g} / \mathrm{kg}$, as well as a control dose of saline, actually increased saccharin consumption slightly.

The present experiments were designed to determine whether intraperitoneal injections of ethanol, in doses of $1.2 \mathrm{~g} / \mathrm{kg}$ or less, which are often used in behavioral studies, would produce conditioned aversion. The training and testing procedures of Lester et al were modified in two ways in an attempt to increase the likelihood of producing and detecting aversion. First, it seemed likely that several pairings of ethanol with a distinctly flavored solution would be more likely to

\footnotetext{
*This research was supported by Training Grant MH 12640-02 from the National Institute on Alcohol Abuse and Alcoholism and Grant MH 23607-01 from the National Institutes of Health.
}

produce conditioned aversion than the single pairing used by Lester et al. Second, a two-flavor preference-drinking test was used in place of, and in combination with, the single-flavor forced-drinking test employed by Lester et al, since it offered increased promise of detecting low levels of conditioned aversion. As Dragoin, McCleary, and McCleary (1971) and Grote and Brown (1971) have shown, the two-stimulus test is more sensitive than the single-stimulus method. Accordingly, in our first experiment, ethanol doses of $1.2 \mathrm{~g} / \mathrm{kg}$ and below were administered intraperitoneally on four occasions immediately after rats had ingested a preferred flavor of Kool-Aid. Since different concentrations of alcohol may be absorbed and metabolized at different rates (Kalant, 1971), the concentration of alcohol at two of the doses was also varied. Single-solution tests during conditioning and two-solution preference tests preceding and following conditioning were used to assay conditioned aversion in experimental and control Ss.

\section{EXPERIMENT I}

\section{Method}

Subjects and Procedure. The Ss were 56 naive Sprague-Dawley-derived female albino rats from Carworth Farms, Inc., Portage, Michigan, randomly assigned to seven groups of 8 members each. Throughout the study, and for a minimum of 10 days prior to the beginning of the experiment, the animals were housed individually in a reversed 12 -h day-night cycle room. An ad lib food and water regimen was in force during the 10-day habituation period, after which the animals were placed on a fluid deprivation schedule that permitted 10 min of drinking per day at the same time each day during the dark cycle. For the first 2 days of fluid deprivation, the 10-min drinking sessions (water from a single drinking tube) were followed by 3-min handling and taming sessions for each animal.

Each day thereafter, the animals were weighed and permitted to drink fluid for $10 \mathrm{~min}$ from either of two drinking tubes that projected through the mesh fronts of the cages on the right-front and middle-front areas. Food was available ad lib throughout the experiment from containers mounted against the left front of the cages.

On Days 1-3 of the experimental schedule, water was presented for $10 \mathrm{~min}$ in one of the two drinking tubes, its position being alternated daily. On Day 4 , the animals were given Kool-Aid to drink, grape flavor in one tube and orange in the 
Table 1

Treatments Accorded the Five Experimental and Two Control Groups $(\mathbf{N}=8 /$ Group)

\begin{tabular}{cccc}
\hline Group & $\begin{array}{c}\text { ETOH } \\
\text { Dose } \\
(\mathrm{g} / \mathrm{kg})\end{array}$ & $\begin{array}{c}\text { Concen- } \\
\text { tration } \\
(\mathrm{v} / \mathrm{v})\end{array}$ & $\begin{array}{c}\text { Volume } \\
\text { Injected } \\
(\mathrm{cc} / \mathrm{kg})\end{array}$ \\
\hline 1 & 0.4 & $20 \%$ & 2.5 \\
2 & 0.8 & $20 \%$ & 5.0 \\
3 & 1.2 & $20 \%$ & 7.5 \\
4 & 0.4 & $6.75 \%$ & 7.5 \\
5 & 0.8 & $13.5 \%$ & 7.5 \\
$6^{*}$ & & & (Saline) 7.5 \\
$7 \dagger$ & 1.2 & $20 \%$ & 7.5 \\
\hline
\end{tabular}

Note-The alcohol solutions were mixed in physiological saline, the percentage being determined by volume alcohol/total volume solution.

*Saline control

tUnpaired control-ETOH injected $2-3 \mathrm{~h}$ after ingestion of preferred flavor.

other. The formula was $0.25 \mathrm{tsp}$ Kool-Aid, $1.5 \mathrm{tsp}$ sugar, and $1.5 \mathrm{c}$ of water at room temperature. The position of the tubes was switched halfway through the drinking session. On Day 5, the animals were given water (the position of the full tube being varied from where it had been on the previous water-drinking day), and on Days 6 and 7, the two Kool-Aid flavors were offered simultaneously to determine flavor preferences. Fluid consumptions were recorded, and the flavor with the highest 2-day total was designated the "preferred flavor." It was used as the "conditioned stimulus" on the subsequent conditioning days. Water drinking was permitted on Day 8 . On all of the latter 8 days, $2-3 \mathrm{~h}$ after the drinking session, each $\mathrm{S}$ received an injection of physiological saline at the same volume $/ \mathrm{kg}$ as it was scheduled to receive on the conditioning days. This procedure was designed to accustom the animals to receiving IP injections.

Conditioning trials were given on Days 9-12. Each animal's preferred flavor was presented in one tube for $10 \mathrm{~min}$ (the other tube was empty), and the amount drunk was recorded. The positions of the two tubes were alternated daily. Five groups of experimental animals received IP injections of ethanol immediately after the $10-\mathrm{min}$ drinking period had ended. The members of a sixth group were given a saline injection at the same relative time. A seventh group, which served as a control for pseudoconditioning, was given the maximum dose and concentration of ethanol, but the injection was delayed for 2-3 $\mathrm{h}$ following the drinking period. These treatments are summarized in Table 1 .

The 4 conditioning days were followed by 8 days (13-20) of 10 -min preference testing, the positions of the two flavors being alternated daily. All Ss received delayed daily injections of saline of exactly the same kind as they had been given on Days 1-8.

\section{Results}

Daily intakes of the preferred fluid were recorded in milliliters, and averages over either 1- or 2-day periods for each of the seven groups are shown in Fig. 1. An analysis of variance of preconditioning preferential intakes revealed no significant outcomes. Subsequent differences could not be due, therefore, to pretreatment sampling fluctuations. F-max tests on data collected during conditioning and postconditioning phases indicated the need for nonparametric tests. Wilcoxon matched-pairs signed-ranks two-tailed tests were used for within-group comparisons, whereas the Kruskal-Wallis one-way analysis of variance served for between-group comparisons. Mann-Whitney U tests (two-tailed) were used in the follow-up of significant between-group differences.

The single-solution test data gathered during the conditioning phase are plotted in the central section of Fig. 1. It is evident from inspection that the intakes of the three experimental groups given the largest doses of alcohol $(1.2 / 20 \%, .8 / 20 \%, .8 / 13.5 \%)$ declined considerably from Day 9 to Day 12 . The Day 9 data were gathered before the first injection, while the Day 12 data were gathered before the fourth injection.

On Day 12, after three pairings, the intakes of the $1.2 / 20 \%$ and $.8 / 13.5 \%$ groups were significantly below what they had been on Day $9(\mathrm{~T}=0.0, \mathrm{p}<.01$ and $\mathrm{T}=$ $0.0, p<.05$, respectively), but the decrease shown by the $.8 / 20 \%$ group was not. The $.8 / 20 \%$ group differed significantly from the $1.2 / 20 \%$ group $(\mathrm{U}=8.5, \mathrm{p}<.02)$ on Day 12 but not from the $8 / 13.5 \%$ group. The first pairing failed to produce a significant decrease in the intake of any group, but four of the five experimental groups drank less on Day 10 than on Day 9. As of Day 12, no evidence of conditioned aversion was provided by the intakes of the unpaired group, the saline controls, or the two $.4 \mathrm{~g} / \mathrm{kg}$ groups.

Individual intakes on the two-solution preference tests were averaged over 2 days to control for position preferences. The group medians have been plotted in Fig. 1. Comparisons of preconditioning with postconditioning intakes (Days 6-7 vs Days 13-14) revealed that the preferred-flavor consumptions of the $1.2 / 20 \%, .8 / 20 \%, .8 / 13.5 \%$, and $.4 / 6.75 \%$ groups were all significantly lower on Days 13-14 than on Days 6-7. The associated significance levels were $\mathrm{T}=0.0, \mathrm{p}<.01$; $\mathrm{T}=0.0, \mathrm{p}<.01 ; \mathrm{T}=0.0, \mathrm{p}<.01 ; \mathrm{T}=3.5, \mathrm{p}<.05$, respectively. Between-group comparisons, based on the data of Days 13-14, showed that the $1.2 / 20 \%$ group was significantly different from every other group. The $.8 \mathrm{-g} / \mathrm{kg}$ groups did not differ reliably from one another nor from the $: 4 / 6.75 \%$ group. With the exception of the $.8 / 20 \%$ group, none of the groups showed significant intake changes over the 8-day preference-test period. The $.8 / 20 \%$ group exhibited a significant increase in consumption of the preferred flavor on the last 2-day period $(\mathrm{T}=2.0, \mathrm{p}=.02)$.

Where dose levels were identical, i.e., in the two $.4-\mathrm{g} / \mathrm{kg}$ and the two $.8 \mathrm{~g} / \mathrm{kg}$ groups, the degree of conditioned aversion appeared to vary directly with the volume and inversely with the concentration. Thus, the $.8 / 13.5 \%$ group suppressed more than the $.8 / 20 \%$ group during conditioning and during the preference tests, even though the differences were not significant. Likewise, the $.4 / 6.75 \%$ group suppressed more than the $.4 / 20 \%$ group, but, again, not significantly.

\section{Discussion}

The results of the first experiment were consistent with the expectation that intraperitoneal injections of relatively low doses of alcohol can produce conditioned aversion. A previous study (Lester et al, 1970) failed to 


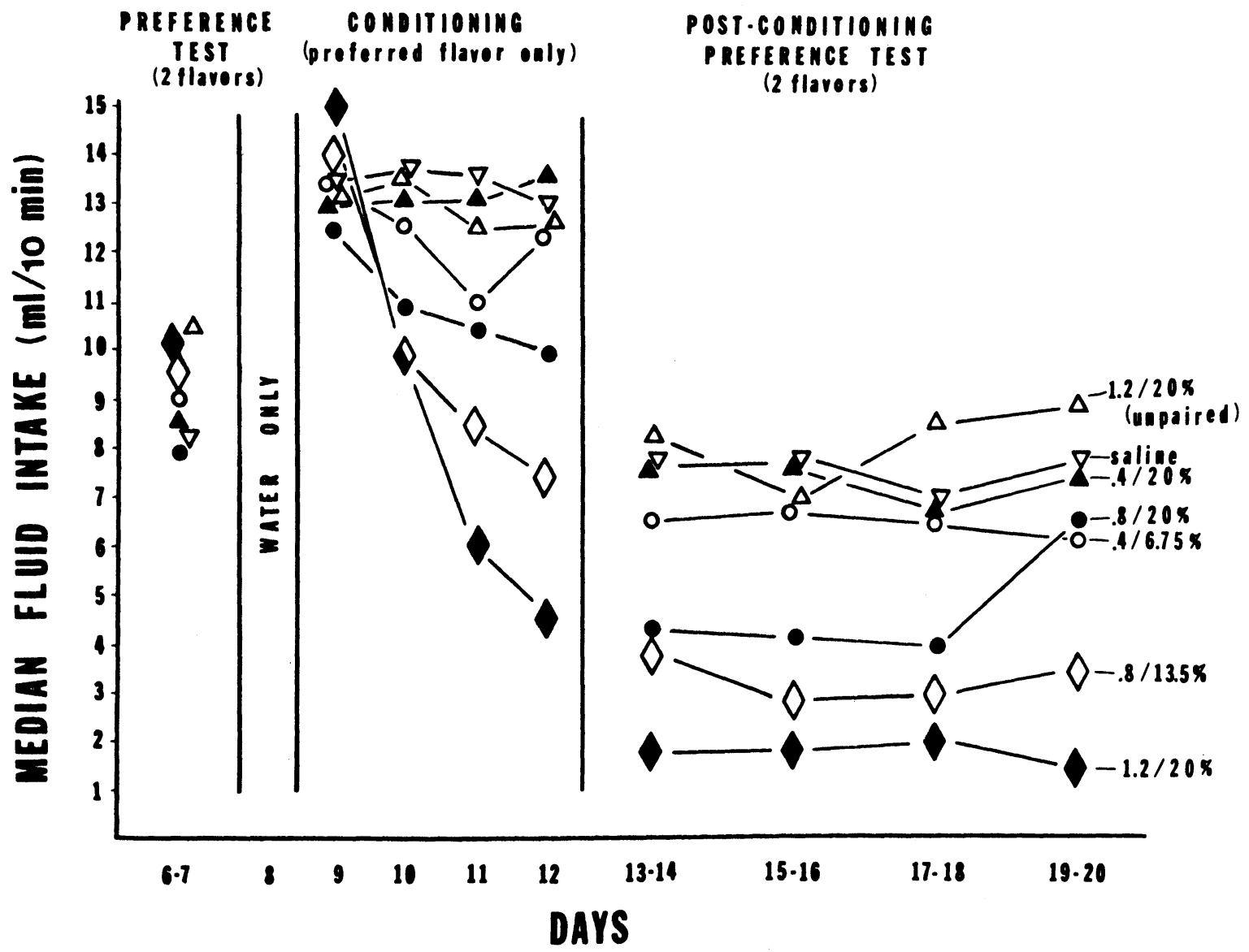

Fig. 1. Median fluid intake of the preferred flavor for preference sessions, conditioning sessions, and postconditioning sessions. Ss had a two-choice situation on preference and postconditioning sessions, while only the preferred flavor was available on conditioning sessions.

tect aversion at such low dosages, but only one nditioning trial was administered and the test for ersion, a single-stimulus forced-drinking test, may have :ked sensitivity. In our experiment, the single-stimulus ocedure likewise failed to detect conditioned aversion llowing a single pairing of alcohol with the preferred lid, though after three pairings it was clearly evident in $21.2 / 20 \%$ and the $.8 / 13.5 \%$ groups. By comparison, 2 two-solution method revealed conditioned aversion lowing four injections of alcohol of only $.4 / 6.75 \%$ sh. A dose of this level produces no visible signs of oxication in the rat. The highest dose levels used in $s$ study $(1.2 \mathrm{~g} / \mathrm{kg})$ did produce signs of inebriation activity and/or loss of balance), but conditioned rrsion was not obtained when the dose was delayed - 2-3 $\mathrm{h}$ following the drinking period. These Ss were ver observed to be in a comatose state. Saline ections given immediately after the drinking period 0 failed to produce conditioned aversion, which ues against the possibility that the needle-produced n was primarily responsible for the aversion tcomes.

The fact that the two-solution preference test ected conditioned aversion at the lowest dosage used, ereas the single-solution method did not, cannot be attributed simply to the greater sensitivity of the former method in our experiment, since only three pairings entered into the single stimulus results whereas four such pairings were involved in the preference-test data. It must also be noted that the decreased intakes were not due simply to the animal's learning not to drink any fluids. On Days 13-14, for example, the $1.2 / 20 \%$ paired group, which showed the maximum conditioned aversion to the preferred flavor, increased its consumption of the nonpreferred flavor from 3.75 to $10.0 \mathrm{ml}$.

Finally, the results cannot reasonably be attributed to a carry-over in the form of nausea or sickness from the alcohol injections to the test on the following day. If the latter were the case, the $1.2 \mathrm{~g} / \mathrm{kg}$ unpaired group should have shown the most dramatic decrease in consumption on both the single-stimulus and double-stimulus tests. In point of fact, however, the unpaired group showed no evidence of conditioned aversion on either test.

\section{EXPERIMENT II}

Insofar as possible, all of the Ss of the first experiment were handled and injected identically regardless of the group to which they belonged. 
Nevertheless, since the Es knew which solutions were being used, the possibility remains that dose-related aversion could have been produced unwittingly by differential handling. To control for this possibility and to extend the generality of the initial findings, a second study was conducted in which blind techniques were used and in which other procedural changes were introduced.

\section{Method}

Subjects. The Ss were 16 naive female albino rats (Sprague-Dawley derivatives) 90-130 days old. They were from a different supplier (Simonsen Laboratories, Gilroy, California) than were the ones that had been used in Experiment I.

Procedure. Upon receipt from the supplier, the animals were randomly assigned to two groups of eight members each. They were housed in individual cages in a room where the normal day-right light cycle rather than a reversed cycle was in effect. On conditioning days, every rat was given two injections a day rather than a single injection as in Experiment $I$. The experimental group was given alcohol $(1.2 \mathrm{~g} / \mathrm{kg}-20 \% \mathrm{v} / \mathrm{v})$ immediately after the 10-min drinking period, while the control animals received saline of equal volume $/ \mathrm{kg}$. Two to three hours later, the controls were given the same volume of alcohol as they had previously had of saline, while the experimental Ss received a volume of saline which equaled that of their earlier injection of alcohol. Pseudoconditioning or sensitization-like effects should therefore be equated by this method. The 10 -min drinking period occurred during the light phase of the day rather than in the dark, and the $\mathrm{E}$ who gave the injections was not informed as to the substance being injected. In all other respects, the procedures were the same as those of Experiment I.

\section{Results and Discussion}

As before, the groups did not differ significantly at the start of the 4-day conditioning phase. Although both groups demonstrated significant decreases in consumption from the first to the last day of conditioning (experimental-T $=0.0, \mathrm{p}<.01$; control-T $=0.0, \mathrm{p}=.02$ ), the experimental group was significantly lower in its consumption than was the control group on the last day $(\mathrm{U}=7.0, \mathrm{p}<.01)$. Likewise, although both groups demonstrated significant decreases in the consumption of the originally preferred flavor on the first 2 -day block following conditioning (experimental $-\mathrm{T}=1.0, \mathrm{p}<.02$; control $-\mathrm{T}=0.0, \mathrm{p}=$ $.05)$, the experimental group was significantly lower than the control group $(U=11.5, p<.05)$. For reasons that are not clear, both groups became highly variable thereafter, and significant differences were not systematically attained. Thus, although hoth groups demonstrated a decrease in consumption of the preferred flavor, the experimental group was significantly lower on all of the conditioned aversion measures than the control group. It is possible that the decrease for the control group may have been due to the administration of two injections per day in spite of the fact that the second was delayed 2-3 h after the first.

In this second experiment, conditioned aversion was again obtained with relatively low dosages of alcohol and under conditions that make an interpretation of $\mathrm{E}$ bias untenable. Moreover, since all animals received both alcohol and saline injections each day, the possibility is reduced that the experimental Ss were drinking less of their preferred fluid simply because they were nauseated or upset by the alcohol whereas the controls were not. These results also argue against the likelihood that the outcome of the first experiment was due to the fact that the animals were maintained under a reversed day-night cycle and were given their daily 10 -min drinking test during the dark phase of the cycle.

\section{REFERENCES}

Barry, H., \& Wallgren, H. A further note on preparing alcohol solutions. Quarterly Journal of Studies on Alcohol, 1968, 29, 176-178.

Dragoin, W., McCleary, G. E., \& McCleary, P. A comparison of two methods of measuring conditioned taste aversions. Behavior Research Methods \& Instrumentation, 1971, 3, 309-310.

Freed, E. X. The effect of alcohol upon approach-avoidance conflict in the white rat. Quarterly Journal of Studies on Alcohol, 1967, 28, 236-254.

Grote, F. W., \& Brown, R. T. Conditioned taste aversions: Two-stimulus tests are more sensitive than one-stimulus tests. Behavior Research Methods \& Instrumentation, 1971, 3, 311-312.

Kalant, H. Absorption, diffusion, distribution, and elimination of ethanol: Effects on biological membranes. In B. Kissin and H. Begleiter (Eds.), The biology of alcoholism: Volume 1. New York: Plenum, 1971.

Lester, D., Nachman, M., \& Le Magnen, J. Aversive conditioning by ethanol in the rat. Quarterly Journal of Studies on Alcohol, 1970, 31, 578-586.

(Received for publication October 24, 1973; revision received November 6,1973 .) 